\title{
A Large Sample Comparison of Grade Based Student Learning Outcomes in Online vs. Face-to-Face Courses
}

Joseph K. Cavanaugh and Stephen J. Jacquemin

Wright State University - Lake Campus

\begin{abstract}
Comparisons of grade based learning outcomes between online and face-to-face course formats have become essential because the number of online courses, online programs and institutional student enrollments have seen rapid growth in recent years. Overall, online education is largely viewed by education professionals as being equivalent to instruction conducted face-to-face. However, the research investigating student performance in online versus face-to-face courses has been mixed and is often hampered by small samples or a lack of demographic and academic controls. This study utilizes a dataset that includes over 5,000 courses taught by over 100 faculty members over a period of ten academic terms at a large, public, four-year university. The unique scale of the dataset facilitates macro level understanding of course formats at an institutional level. Multiple regression was used to account for student demographic and academic corollaries-factors known to bias course format selection and grade based outcomes - to generate a robust test for differences in grade based learning outcomes that could be attributed to course format. The final model identified a statistical difference between course formats that translated into a negligible difference of less than 0.07 GPA points on a 4 point scale. The primary influence on individual course grades was student GPA. Interestingly, a model based interaction between course type and student GPA indicated a cumulative effect whereby students with higher GPAs will perform even better in online courses (or alternatively, struggling students perform worse when taking courses in an online format compared to a face-to-face format). These results indicate that, given the large scale university level, multi course, and student framework of the current study, there is little to no difference in grade based student performance between instructional modes for courses where both modes are applicable.
\end{abstract}

\section{Introduction}

By almost every measure, online education continues to play an increasing role in higher education. A recent survey by Allen and Seaman (2013) of over 2,800 universities and colleges found that $32 \%$ of students - over 6.7 million total - are taking at least one online course. While the annual growth rate of online enrollment has slowed from an extremely rapid $30 \%+$ rate of ten years ago, it is still 
increasing at a rate of over $9 \%$ every year. This growth rate is not surprising since almost $70 \%$ of higher education academic leaders believe that online education is crucial for their long-term strategy. Although historically many institutions met online education with resistance, over the past 10 years, the percentage of academic leaders that rate the quality of online classes equivalent or higher than face-to-face classes has steadily increased from about $52 \%$ to $77 \%$.

Meta-analytic work spanning the past several decades has identified negligible to modest differences in student performance between online and face-to-face course formats (Bernard et al., 2004; Zhao et al., 2005; Tallent-Runnels et al., 2006; Means et al., 2009). These meta-analyses do indicate significant variation between studies related to study design approach, study objectives, and measured student based learning or performance outcomes. To the extent that online courses are different than faceto-face courses, the grade students receive (i.e. performance) compared to the identical course taught in the alternative format should differ. There is a distinct need in the literature for larger scale studies to test these hypotheses that utilize single uniform institutional datasets composed of a variety of colleges, courses, and students. This paper compares grade based student learning outcomes in online and face-toface delivery modes for a wide variety of subjects, courses, and course levels over a four-year period of time.

\section{Literature Review}

Within the academic literature there exists a considerable amount of disagreement about how effective online courses (compared face-to-face courses) are in achieving learning outcomes or educational objectives. Common study objectives within the literature include addressing a range of student based areas such as grade levels (A, B, C, etc.) and disparity, as well as student retention (course and institutional) and matriculation. Most of these studies look at comparisons of online and face-to-face courses taught by one faculty member in one subject at one particular institution. These studies are extremely important as they indicate local scale levels of variation among students; that said, smaller scale studies are not able to suggest institutional level conclusions. Many of these studies are indexed and described in the "No Significant Difference" literature concatenated by Russell (http://nosignificantdifference.org/).

The majority of studies find that there is no difference in grade based student learning outcomes between modes of instruction. For example, Ashby et al. (2011), found no statistical differences in student grades in a developmental math course when taught face-to-face compared to online or blended teaching methods. Similarly, Larson (2009) indicated no statistical difference in grades of students taking an introductory management course. Earlier work by McLaren (2004), also indicated grades of online students in a business statistics course were not significantly different between students completing online compared to face-to-face course offerings. More recently, Driscoll et al. (2012), analyzed grade differences between students taking three online and face-to-face sociology courses. While Driscoll et al. (2012) initially found grades of online students to be significantly worse than their face-to-face peers, after controlling for aptitude (GPA), grade differences between the two course formats were statistically insignificant. Specifically pertaining to larger scale studies, Atchley et al. (2013) utilized a sample of over 5,000 students from a variety of disciplines at a small public school and concurred with these other smaller scale studies that there were no statistically significant differences between student grades of online compared to face-to-face courses.

Some studies have found that online methods of instruction can have negative influences on learning objectives and student grades. For example, numerous studies specifically identify lower grade performance in online compared with face-to-face course sections (Jaggars et al., 2013; Xu \& Jaggars, 2013). Increased grade disparity among students has also been associated with online courses, whereby a larger percentage of student grades of A's, D's and F's are present in online courses where more B's and C's are associated with traditional face-to-face course formats, which suggests increased variation related to bimodal distributions (Atchley et al., 2013). Jaggars et al. (2013) point out that online courses seem to exacerbate achievement disparities that can occur between students taking face-to-face courses and 
parallel reduced course completion rates. Similarly, Xu and Jaggars (2013), in a large sample of students enrolled in 34 two-year public Washington State community colleges, found that students ultimately perform worse in online courses and were also more susceptible to dropping out compared to students in face-to-face formats (Xu \& Jaggars, 2013). Relative to performance outcomes on short vs. long term scales in online and face-to-face courses, Johnson and Mejia (2014) indicate that while higher grade variation and lower completion rates are present in online modes, those students that do complete an online course tend to have higher program completion rates. Shea and Bidjerano (2014) also found that after controlling for student attributes, those students taking courses in online formats actually maintain higher matriculation rates to graduation.

Course format modes are often found to significantly relate to particular student populations and demographic attributes (Stewart et al., 2010). These corollaries indicate a need to understand student attributes to appropriately describe trends between online and face-to-face courses. In addition to the grade similarities between online and face-to-face format modes, Ashby et al. (2011) described particular demographic corollaries of course formats. For example, older students and female students in general were more likely to enroll in the online course sections, but minorities were more likely to enroll in faceto-face course sections. Larson (2009) also found that a larger percentage of minorities and male students enroll in face-to-face course sections. Driscoll et al. (2012) found that students taking online courses tend to be older and added that online students also tend to have lower GPAs and work a greater number of hours per week outside of class. Relative to student preparedness as a description of students, $\mathrm{Xu}$ and Jaggars (2013) suggest that preparation levels between students taking online courses and students taking traditional face-to-face courses may be different, particularly between subject areas.

Some studies have attempted to explain why students in online classes may have different grade based learning outcomes from students in face-to-face classes. Calafiore and Damianov (2011) suggest that one reason students taking online courses perform worse than their face-to-face peers is due to differences in course participation habits. Using a data set from five online economics and five online finance courses, Calafiore and Damianov (2011) found that the higher the student's GPA and the more time students spent doing online course work, the better their performance in online formats. Differences in student conduct have also been suggested as a potential explanatory mechanism. However, Hollister and Berenson (2003) provide evidence that the online course format is not necessarily associated with an increase in academic conduct issues (e.g. cheating) compared to face-to-face formats. Moreover, Hollister and Berenson (2003) found no significant difference in students' grades when taking proctored in-class exams versus online non-proctored exams. Similarly, Hallock et al. (2003) examined the performance of 75 undergraduate business students and found no significant differences in learning styles and ultimately, the grade received by online students. They also found no statistically significant relationships between age, gender, or race with learning styles of online students.

The objective of the present study was to incorporate a large data set of online and face-to-face course outcomes from a single university spanning multiple terms while controlling for often confounding demographic and academic corollaries to generate a robust test for differences in grade based learning outcomes as pertaining to course format.

\section{Methods}

To investigate online vs. face-to-face grade differences (student performance), course level data were obtained from a large Midwest public university. Course level data included mean student values for academic (online or face-to-face course format, course GPA, student credit hours, student GPA, college) and demographic (gender, minority status, age) variables. Since the focus of this study is on the comparison of grades between online and face-to-face courses, only courses that were taught in both formats (at least once) by the same instructor were included. The sample therefore consisted of every course taught at the institution over a three year time period that was taught in both an online and a faceto-face format at least once by the same faculty member over this time period. For example, if Professor 'Smith' taught ENG 101 once (or more) in both an online and face-to-face format during this time period, 
then all sections of ENG 101 taught by him over this time period were included in the sample. If Professor 'Smith' did not teach any ENG 101 sections in either an online or face-to-face format, then none of his or her courses would be included in the sample. The suite of academic and demographic variables was included to serve as a control for parsing out variation actually attributable to a difference in course delivery mode. These academic and demographic variables have been supported in the literature to strongly covary with academic performance. Thus, these variables should be factored into any analysis involving student performance as a series of covariates to avoid selectivity bias. For example, nonminority, older, female students and students with higher GPAs are more likely to enroll in online courses (Cavanaugh, 2005; Xu \& Jaggars, 2013). Also, in general, it is more likely that students with higher GPAs will achieve higher scores in classes regardless of the mode of delivery. If these variables were not included in the model, then a finding that online courses are associated with higher grades could be confounded by a particular demographic or academic attribute of the students enrolling, and not because the course was being taught in an online vs. face-to-face format. Other variables may also exhibit direct or indirect relationships with the variable of interest. Future analyses should incorporate these given data availability.

Table 1. Mean student course attributes combined and separated by instruction type.

\begin{tabular}{cccc}
\hline Variable & \multicolumn{3}{c}{ Means } \\
\hline & All & Online & F2F \\
\cline { 2 - 4 } Observations & 6012 & 1997 & 4015 \\
Student GPA & 3.15 & 3.41 & 3.02 \\
Student Credit Hours & 74.25 & 72.54 & 75.11 \\
Gender (Male) & 0.43 & 0.39 & 0.44 \\
Minority & 0.22 & 0.20 & 0.23 \\
Age & 26.98 & 30.00 & 25.48 \\
CEHS Courses & --- & 621 & 660 \\
COB Courses & --- & 240 & 356 \\
COLA Courses & --- & 473 & 1764 \\
CONH Courses & --- & 223 & 248 \\
COSM Courses & --- & 207 & 580 \\
CECS Courses & --- & 233 & 404 \\
OTHER Courses & --- & 0 & 3 \\
\hline
\end{tabular}

Ordinary least squares regression (OLS) was used to test for the effect of course type on overall course GPA. Ordinary least squares regression is a technique useful for assessing the relationship between an $x$ and $y$ variable where a linear relationship is expected (e.g. grades). Ordinary least squares regression has been used in previous analyses assessing student performance in online vs. face-to-face course types (Driscoll et al., 2012). Of particular use in this context is the ability to run multiple models gradually including explanatory variables to predict student performance. The ordinary least squares approach facilitates the recognition of direct and indirect corollaries of student performance in a given course type. Our initial model utilized a single term approach explaining course GPA as a function of online vs. faceto-face course type. Five models of increasing saturation were then used to parse out the amount of variation explained by other academic and demographic variables irrespective of online vs. face-to-face course types (Driscoll et al., 2012). Given the many direct and indirect relationships associated with these types of data, the issue of multi-collinarity should be addressed. Multi-collinarity is a commonly occurring problem when conducting regression analysis that can lead to erroneous conclusions. Multi- 
collinearity associated with independent variables was assessed using variance inflation factor values (Fox \& Weisberg, 2011). To reduce non-essential multicollinarity between first order variables and their respective interactions (only one interaction included) a mean centered approach was used for student GPA (Dalal \& Zickar, 2012). All analyses were implemented using the car package in the R statistical environment (R Core Team, 2013).

\section{Results}

The study included information from 140,444 students enrolled in 6,012 courses between 2010 and 2013. The courses included 1,997 online and 4,015 face-to-face offerings. Students in online classes tended to be older in age, female, non-minority, and have higher academic GPAs despite similar total credit hours enrolled (Table 1). Overall, all independent variables except for minority status were found to relate to course GPA (Table 2). Our initial model to predict student grades as a function of course format was positive and highly significant, explaining approximately $39 \%$ of the variability in course performance (Table 2). This suggests that students in online courses will receive a grade point average that is 0.39 points (almost $40 \%$ of a letter grade) higher than a student taking a face-to-face course (Table 2).

Table 2. Regression models describing sources of variation in student performance.

\begin{tabular}{|c|c|c|c|c|c|}
\hline $\begin{array}{l}\text { Independent and Control } \\
\text { Variables }\end{array}$ & Model 1 & Model 2 & Model 3 & Model 4 & Model 5 \\
\hline Course type (online) & $\begin{array}{l}0.390 * * * \\
(0.020)\end{array}$ & $\begin{array}{l}0.157 * * * \\
(0.010)\end{array}$ & $\begin{array}{l}0.097 * * * \\
(0.018)\end{array}$ & $\begin{array}{l}0.100 * * * \\
(0.018)\end{array}$ & $\begin{array}{l}0.066^{* * *} \\
(0.018)\end{array}$ \\
\hline Student GPA & & $\begin{array}{l}0.554 * * * \\
(0.018)\end{array}$ & $\begin{array}{l}0.464 * * * \\
(0.014)\end{array}$ & $\begin{array}{l}0.410^{* * *} \\
(0.014)\end{array}$ & $\begin{array}{l}0.373^{* * *} \\
(0.015)\end{array}$ \\
\hline Student credit hours & & $\begin{array}{l}0.0004^{* *} \\
(0.0001)\end{array}$ & $\begin{array}{l}0.0003^{*} \\
(0.0002)\end{array}$ & $\begin{array}{l}0.001^{* *} \\
(0.0002)\end{array}$ & $\begin{array}{l}0.001^{* * *} \\
(0.0002)\end{array}$ \\
\hline Gender (male) & & & $\begin{array}{l}-0.329 * * * \\
(0.028)\end{array}$ & $\begin{array}{l}-0.249 * * * \\
(0.029)\end{array}$ & $\begin{array}{l}-0.251 * * * \\
(0.029)\end{array}$ \\
\hline Minority & & & $\begin{array}{l}-0.019 \\
(0.037)\end{array}$ & $\begin{array}{l}0.053 \\
(0.038)\end{array}$ & $0.042(0.038)$ \\
\hline Age & & & $\begin{array}{l}0.018 * * * \\
(0.001)\end{array}$ & $\begin{array}{l}0.013 * * * \\
(0.001)\end{array}$ & $\begin{array}{l}0.013^{* * *} \\
(0.001)\end{array}$ \\
\hline CEHS (CECS) & & & & $\begin{array}{l}0.288 * * * \\
(0.032)\end{array}$ & $\begin{array}{l}0.277^{* * *} \\
(0.032)\end{array}$ \\
\hline COB (CECS) & & & & $\begin{array}{l}-0.160^{* * * *} \\
(0.032)\end{array}$ & $\begin{array}{l}-0.169 * * * \\
(0.035)\end{array}$ \\
\hline COLA (CECS) & & & & $\begin{array}{l}-0.041 \\
(0.030)\end{array}$ & $-0.044(0.028)$ \\
\hline CONH (CECS) & & & & $\begin{array}{l}0.107 * * \\
(0.040)\end{array}$ & $0.060 *(0.04)$ \\
\hline COSM (CECS) & & & & $\begin{array}{l}-0.090^{* *} \\
(0.033)\end{array}$ & $\begin{array}{l}-0.100 * * \\
(0.040)\end{array}$ \\
\hline OTHER (CECS) & & & & $\begin{array}{l}0.3371 \\
(0.346)\end{array}$ & $0.342(0.344)$ \\
\hline $\begin{array}{l}\text { Course type } \mathrm{x} \text { Student } \\
\text { GPA }\end{array}$ & & & & & $\begin{array}{l}0.166 * * * \\
(0.030)\end{array}$ \\
\hline Intercept & $\begin{array}{l}3.02 * * * \\
(0.01)\end{array}$ & $\begin{array}{l}1.36 * * * \\
(0.04)\end{array}$ & $\begin{array}{l}1.303^{* * *} \\
(0.048)\end{array}$ & $\begin{array}{l}1.525 * * * \\
(0.060)\end{array}$ & $\begin{array}{l}2.784 * * * \\
(0.051)\end{array}$ \\
\hline Adjusted R2 & 0.06 & 0.29 & 0.32 & 0.35 & 0.36 \\
\hline
\end{tabular}


This result is contrary to that of Xu and Jaggars (2011; 2013) who find students' grades are lower when taking online courses. However, inclusion of additional variables in subsequent saturated models indicated the majority of this variation was a product of other academic and demographic parameters rather than course delivery mode (Table 2). The final saturated model indicated that the majority of course grade variation can be attributed to a student's GPA. Our results indicate that students with higher GPAs tend to earn higher grades in courses. The final saturated model (Model 5) also showed an interaction between course type and student GPA indicating that students with higher GPAs tend to preferentially select face-to-face courses, and this combination results in the higher course grade. Ultimately, the overall effect of delivery mode in the final saturated model was found to explain less than 0.07 points of variation in course GPA

\section{Discussion}

The overall result of little to no difference between course offering formats is consistent with the "No Significant Difference" literature (http://nosignificantdifference.org/). The significance and sign of the demographic variables were also generally consistent with other studies (Driscoll et al., 2012), which is namely that non-minority, older, female students have higher grades than minority, younger, male students. Of particular interest are the results elicited by interpreting the interaction term within the final saturated model. The interaction between course type and student GPA indicates that students with higher GPAs will perform even better in online courses (or alternatively, struggling students perform worse when taking courses in an online format compared to a face-to-face format). This has implications for student success and advising principles when identifying specific cohorts for online and face-to-face education.

Although this study finds grades, independent of demographic and academic corollaries, to be practically similar regardless of the method of instruction, the sample used was from just one institution and only included courses that could be taught in both formats (e.g. excluded science courses with lab components). Future studies should incorporate additional academic and demographic variables wherever possible to expand the scope of the study. Also, additional universities from the United States as well as elsewhere in the global academic community should be included in future models to account for regional differences in instruction. Furthermore, future studies should separate course types by subject to identify intra-institutional variation in grade performance. Course level grade variation should also be more thoroughly quantified to ensure interactions between student grades do not become exacerbated with online vs. face-to-face course format selection. Course completion and program matriculation become essential pieces of assessment and represent two aspects of scale to provide a clearer short and long term measure of the impact of online vs. face-to-face instruction.

\section{Conclusion}

The landscape of higher education has been the subject of much discussion with recent technological advances. Although teaching technologies and methodologies are always changing, the rapid and ongoing growth of online teaching suggests that this format will be increasingly used in the future (Aslanian \& Clinefelter, 2013). Of course, widespread adoption of any technology or methodology does not itself serve as a panacea for higher education. Changes to instructional formats should always be supported by rigorous studies that identify both improvements and shortcomings of each new or old instructional mode relative to learning outcomes. Ultimately, as online education programs continue to grow, success and failure of one format or another should be gauged through instructional content, grade based outcomes, grade disparity, course completion rates, program matriculation, as well as qualitative aspects of higher education. 


\section{References}

Allen, I. E., \& Seaman, J. (2013). Changing course: ten years of tracking online education in the United States. Babson Survey Research Group and Quahog Research Group, LLC. Retrieved from http://www.onlinelearningsurvey.com/reports/changingcourse.pdf.

Ashby, J., Sadera, W. A., \& McNary, S. W. (2011). Comparing student success between developmental math courses offered online, blended, and face-to-face. Journal of Interactive Online Learning, 10(3), 128-140.

Aslanian, C. B., \& Clinefelter, D. L. (2013). Online college students 2013: Comprehensive data on demands and preferences. Louisville, KY: The Learning House, Inc. Retrieved from http://www.learninghouse.com/ocs2013-report/.

Atchley, W., Wingenbach, G., \& Akers, C. (2013). Comparison of course completion and student performances through online and traditional courses international. Review of Research in Open and Distance Learning, 14(4), 104-116.

Bernard, R.M., Abrami, P.C., Lou, Y., Borokhovski, E., Wade, A., Wozney, L., . . . Huang, B. (2004). How does distance education compare to classroom instruction? A meta-analysis of the empirical literature. Review of Educational Research, 74, 379-439.

Calafiore, P., \& Damianov, D. S. (2011). The effect of time spent online on student achievement in online economics and finance courses. The Journal of Economic Education, 42(3), 209-223.

Cavanaugh, J. K. (2005). Are online courses cannibalizing students from existing courses? Journal of Asynchronous Learning Networks, 9(3), 3-8.

Dalal, D. K., \& Zickar, M. J. (2012). Some common myths about centering predictors in moderated multiple regression and polynomial regression. Organization Research Methods, 15, 339-362.

Driscoll, A., Jicha, K., Hunt, A. N., Tichavsky, L., \& Thompson, G. (2012). Can online courses deliver in-class results? A comparison of student performance and satisfaction in an online versus a faceto-face introductory sociology course. Teaching Sociology, 40(4), 312-331.

Fox, J., \& Weisberg, S. (2011). An R companion to applied regression (2nd ed.). Thousand Oakes, CA: Sage Publishing.

Hallock, D., Satava, D., \& LeSage, T. (2003). An exploratory investigation of the potential relationship between student learning styles, course grade, cumulative grade point average and selected demographics in on-line undergraduate business. Courses Management Research News, 26(1), 21-28.

Hollister, K. K., \& Berenson, M. L. (2009). Proctored versus unproctored online exams: studying the impact of exam environment on student performance decision sciences. Journal of Innovative Education, 7(1), 271-294.

Jaggars, S. S., Edgecombe, N., \& Stacey, G. W. (2013). What we know about online course outcomes. New York: Community College Research Center, Teachers College, Columbia University. Retrieved from http://ccrc.tc.columbia.edu/publications/what-we-know-online-courseoutcomes.html.

Johnson, H., \& Mejia, M. C. (2014). Online learning and student outcomes in California's community colleges. San Francisco, CA: Public Policy Institute of California.

Larson, D. K. (2009). Comparing student performance: online versus blended versus face-to-face. Journal of Asynchronous Learning Networks, 13(1), 31-42.

McLaren, C. H. (2004). A comparison of student persistence and performance in online classroom business statistics experiences decision sciences. Journal of Innovative Education, 2(1), 1-10. 
Means, B., Toyam a, Y., Murphy, R., Bakia, M., \& Jones, K. (2009). Evaluation of evidence-based practices in online learning: A meta-analysis and review of online learning studies. Washington, D.C.: U.S. Department of Education, Office of Planning, Evaluation, and Policy Development.

R Core Team. (2013). R: A language and environment for statistical computing [software]. Vienna, Austria: R Foundation for Statistical Computing. Retrieved from http://www.R-project.org/.

Shea, P., \& Bidjerano, T. (2014). Does online learning impede degree completion? A national study of community college students. Computers \& Education, 75, 103-111.

Stewart, C., Bachman, C., \& Johnson, R. (2010). Students' characteristics and motivation orientations for online and traditional degree programs. Journal of Online Learning and Teaching, 6(2), 367-379.

Tallent-Runnels, M. K., Thomas, J. A, Lan, W. Y., Cooper, S., Ahern, T. C., Shaw, S. M., \& Xiaoming, L. (2006). Teaching courses online: A review of the research. Review of Educational Research, 76(1), 93-135.

Xu, D., \& Jaggars, S. S. (2011). The effectiveness of distance education across Virginia's community colleges: evidence from introductory college-level math and English courses. Educational Evaluation and Policy Analysis, 33(3), 360-377.

Xu, D., \& Jaggars, S. S. (2013). Adaptability to online learning: differences across types of students and academic subject areas (CCRC Working Paper No. 54). New York: Community College Research Center, Teachers College, Columbia University. Retrieved from http://ccrc.tc.columbia.edu/publications/adaptability-to-online-learning.html.

Xu, D., \& Jaggars, S. S. (2013). The impact of online learning on students' course outcomes: evidence from a large community and technical college system. Economics of Education Review, 37, 4657.

Zhao, Y., Lei, J., Yan, B., Lai, C., \& Tan, H. S. (2005). What makes the difference? A practical analysis of research on the effectiveness of distance education. Teachers College Record, 107(8), 18361884. 